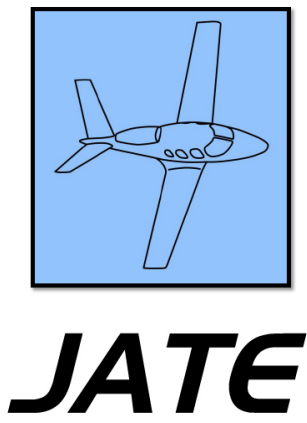

Journal of Aviation Technology and Engineering 5:1 (2015) 44-52

\title{
An Integrated Framework for Fostering Human Factor Sustainability and Increased Safety in Aviation Ramp Operations
}

\author{
Sarah M. Hubbard and Denver Lopp \\ (Purdue University)
}

\begin{abstract}
The aviation work environment has one of the highest accident rates of any industry sector in the United States, resulting in significant costs for both employee injuries and equipment damage. In fact, injury rates exceed rates found in areas that are widely recognized as hazardous, such as construction and mining, and it is estimated that aircraft ground damage costs are as high as 5 billion to 10 billion dollars per year. Purdue University's Aviation Technology Department has conducted numerous safety and human factors studies in the past decade encompassing maintenance and repair operations, corporate flight departments, and over ten major airlines. Based on the accumulated knowledge gained from these studies, a systematic method to reduce workplace costs associated with aircraft damage and worker injuries has been developed. This concept paper summarizes the resulting best practices and methods, which are centered on four main themes: (1) organizational infrastructure, (2) systematic process, (3) measurement, and (4) education. Successfully addressing components related to these four areas has been a major driver and the key to successful ramp operations in the commercial passenger aviation sector. This framework has been used to successfully develop, implement, and maintain and manage human factors sustainability, which refers to creating and maintaining a sustainable environment in terms of the human factors needed to safely and efficiently conduct operations in the aviation environment.
\end{abstract}

Keywords: human factors, safety, aviation work force, aircraft damage, safety culture, sustainability

\section{About the Authors}

Sarah M. Hubbard is an Assistant Professor in Aviation Technology at Purdue University. Prof. Hubbard is a licensed, professional civil engineer with experience in industry, research, and academics. Prof. Hubbard conducts research in planning, operations, and safety. Prof. Hubbard has BS and PhD degrees from Purdue University, and an MS degree from Texas A\&M University. Correspondence concerning this article should be sent to sarahh@purdue.edu.

Denver Lopp is a Professor of Aviation Technology at Purdue University. Prof. Lopp's nontraditional teaching and research concepts have gained national and international recognition for Purdue's Aviation Technology Department in producing the next generation of aviation managers and providing practical solutions for today's industry issues. By focusing on bridging academic education with industry practices, Prof. Lopp has developed aviation industry partnerships and conducted numerous research projects. Prior to Purdue, Professor Lopp held several maintenance managerial positions for Pan American World Airways in New York and managed Pan Am's Cargo Methods, Standards, and Budget Department. Prof. Lopp also has a strong background in finance and has owned a multi-office commodity trading company. Prof. Lopp holds an Airframe and Powerplant certificate, is a private pilot, has been a Certificate Member of the American Association of Airport Executives, and has served on several national aviation organization boards and committees. 


\section{Introduction}

Aviation is the safest mode for passenger travel in the United States, as evidenced by the death rates illustrated in Figure 1. Although many people are apprehensive about air travel, in fact, air travel is more than 200 times safer than travel in a motor vehicle (National Safety Council, 2011). The safety of the aviation system is ensured through tight regulation of aircraft and pilots and well developed protocol for procedures at every stage: in the cockpit, in the cabin, and through the services provided by air traffic control, maintenance, and dispatch.

Unfortunately, outside the aircraft, when the aircraft lands on the ground and transitions out of the area controlled by air traffic control or ground control, safety diminishes considerably, as shown in Figure 2. In fact, workers in the scheduled air transportation sector have a nonfatal injury rate more than twice the national average, exceeding not only the US average, but also traditionally high risk sectors such as coal mining, forestry and logging, and construction (Bureau of Labor Statistics (BLS), 2012).

Not surprisingly, the high injury rate in the airline sector translates into higher than average lost work days, as shown in Figure 3 (BLS, 2010). The injury rate in the airline industry is more than twice the national average, and the number of injuries that result in days missed from work is more than three times the national average; furthermore, the incidence in the airline industry is higher than sectors that are traditionally considered high risk, specifically mining and construction (cases are per year per 100 employees). The impact of injuries and lost work in the United States is substantial. In fact, for all industries in the United States, the total cost for nonfatal injuries has been estimated at $\$ 186$ billion, which is based on an average cost of $\$ 21,700$ for each of the 8.559 million injuries annually (Leigh, 2011). While medical costs are a significant consideration, they comprise only $27 \%$ of the total cost of workplace injuries, while the remaining $73 \%$ of the total cost of workplace injuries is attributable to indirect costs

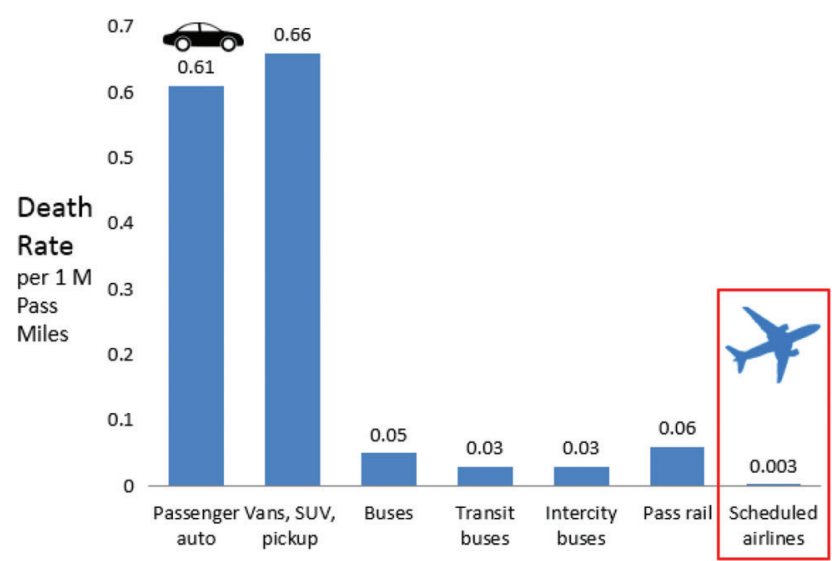

Figure 1. Passenger safety by mode in US, fatality rate per 1 million passenger miles (National Safety Council, 2011).

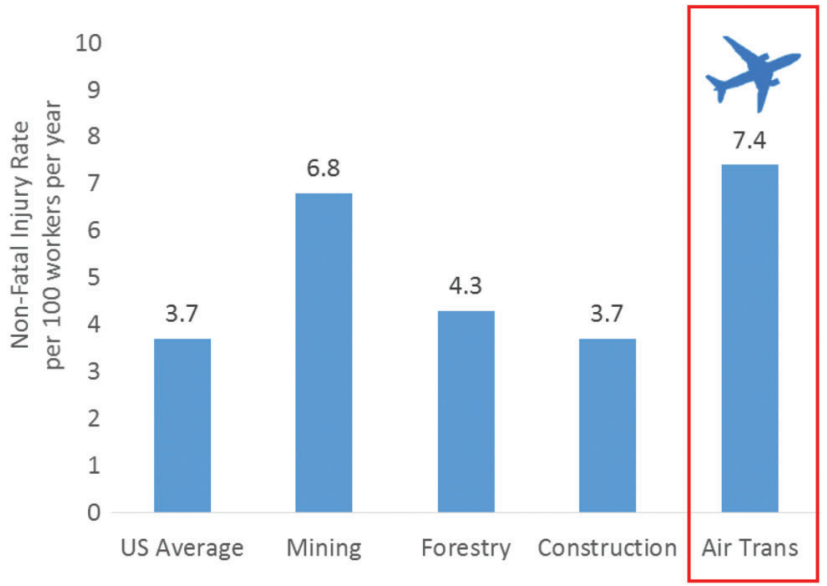

Figure 2 . Worker safety by industry sector (injury rate per 100 workers per year) (Bureau of Labor Statistics (BLS), 2013).

associated with lost wages and worker replacement costs (Leigh, 2011).

The incidence and cost of ramp injuries is significant, and the cost of ramp incidents extends beyond injuries. Many incidents also result in aircraft damage, with an average cost of $\$ 250,000$ per event (Vandel, 2004). Overall estimates for ramp damage were estimated at $\$ 5$ billion in 2004 (Vandel, 2004); adjusting for inflation, this is equivalent to $\$ 6.3$ billion in 2014 (CPI Inflation Calculator, n.d.), which would be equivalent to purchasing 67 Boeing 737-800 aircraft every year, based on an average purchase price of $\$ 93.3$ million in 2014 (Boeing, 2014).

Safety Management Systems (SMS) have been initiated in aviation to provide a comprehensive, process-oriented approach to managing safety. SMS include safety promotion, which encompasses communication and training, as well as safety policy, safety assurance, and safety risk management (FAA, 2014). SMS has been adopted by most airlines (e.g., Liou, Yen, \& Tzeng, 2007; Chen \& Chen, 2012) and is becoming standard in all facets of aviation. While airports may also implement SMS (FAA, 2007), the lack of regulatory requirement has reduced the incentive to do so. In any case, the formal implementation of SMS into the aviation ramp environment has been very limited, and it's not clear that

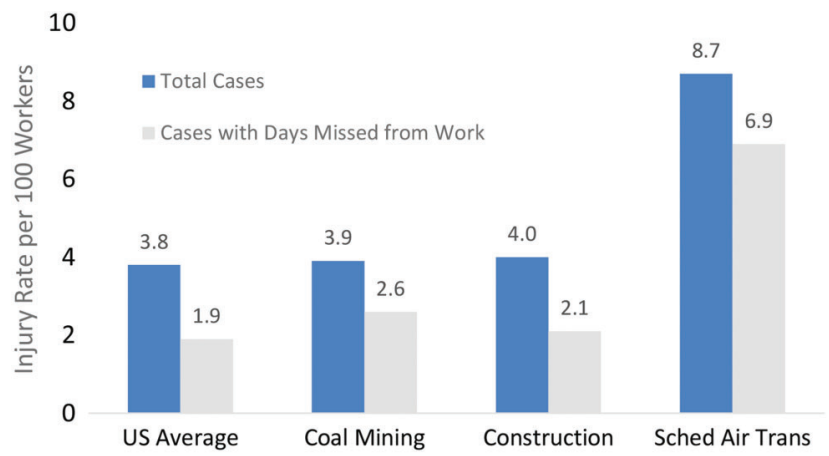

Figure 3. Injuries by industry, total and cases resulting in days missed from work (BLS, 2010). 
traditional SMS alone will assure an adequate level of safety on the ramp. While SMS acknowledges safety culture, it does not outline a comprehensive system for assuring that safety culture is addressed through a sustainable human factors framework.

Ninety-two percent of ramp damage is due to human error and may be attributable to inadequate training, inadequate supervision, failure to follow procedures, work pressures, and inappropriate equipment (Giovanni, 2011). To address and mitigate this high error rate, human error needs to be addressed in the context of not only error attributable to a single person, but also error attributed to the system, which includes culture, system design, and organizational elements (Reason, 2000). The proposed framework for human factors sustainability is a system design that will enable a safe and efficient operation in the aviation environment.

This paper proposes an integrated framework to increase safety and foster human factors sustainability in the aviation ramp environment. Implementation of the framework presented in this document results in improved communication and coordination among team members on the ramp, improved communication and coordination between ramp workers and their supervisors, and improved communication and coordination between ramp supervisors and the managers and executives to whom they report. The increased communication and coordination that results from the proposed framework fosters a safer ramp environment, including a reduced likelihood of damage to aircraft and equipment, as well as reduced likelihood of personnel injury. The purpose of this paper is to describe the theoretical framework for fostering human factors sustainability and increased safety in ramp operations.

\section{A Proposed Framework for Human Factors Sustainability}

Human factors encompasses the development and design of a system to accommodate the interaction of both people and equipment within the environment. Human factors incorporates both the physical and the cultural and psychological factors that affect safe and productive work. Human factors sustainability refers to the development of a working environment, process, and infrastructure that enables the human factors considerations to support the success of operations in the long-term.

The proposed framework for fostering human factors sustainability and increased safety has been developed based on a number of activities including researcher participation in standard airline training programs; observation of actual ramp operations at mainline airport hubs; discussion with airline representatives who oversee ramp operations, ramp training activities, and ramp quality control audits; and follow up with industry representatives during safety workshops. The aforementioned activities led to the identification of four key components to reduce ramp incidents that result in injury and aircraft damage and foster a positive environment for human factors sustainability.

1. Organizational Infrastructure

2. Systematic Process

3. Measurements

4. Education

Organizational Infrastructure. In order for optimal safety to be realized, it must be supported at all levels of the organization. Key players and their roles are shown in Figure 4, which is a variation of a concept originally put forth by Lopp \& Brazee (2005). While some organizational theories suggest a "top down" or a "bottom up" approach, the human factors sustainability model requires ongoing and synergistic activities at all levels of the organization. Employees at all levels have important roles that must be undertaken to achieve sustainability.

Front line employees and supervisors are the primary focus, since they are responsible for day-to-day activities. These employees must be trained, educated and provided with the tools to do their job. These "tools" include not only physical resources, but also ongoing education and cultural support to do their job safely. Brief daily meetings regarding safety and longer weekly meetings with increased

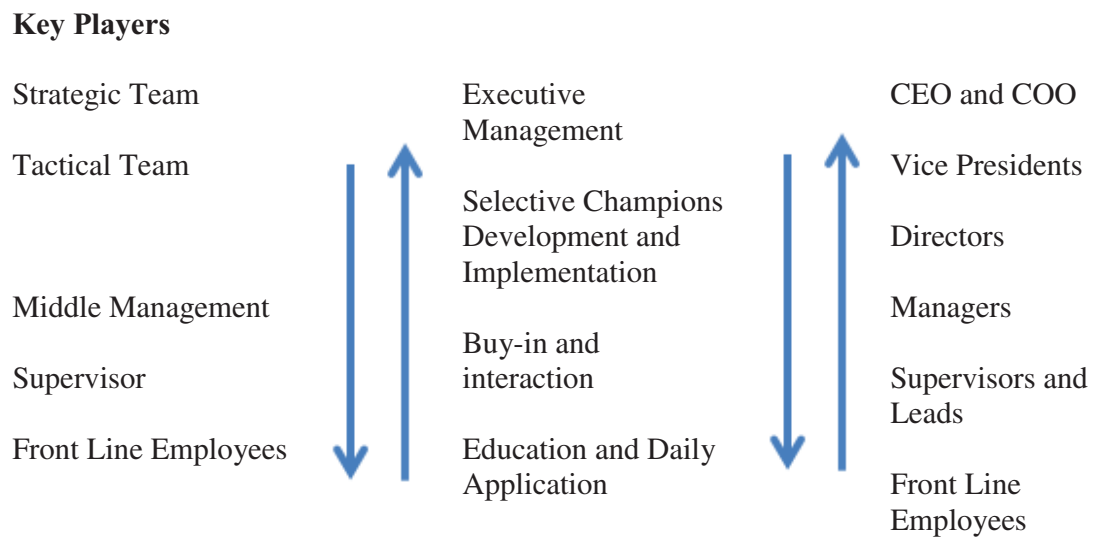

Figure 4. Safety must be supported at all levels of the organization for success. 
content can play an important role in communicating and reinforcing safe operations. Middle management must support supervisors and employees and play a critical role through their "buy-in" by providing a communications link up to the tactical team. The tactical team provides support through the development of appropriate training programs and resources by monitoring measurements related to human factors sustainability and safety. Support of the executive team is imperative, and it must include time and financial resources at all levels to track progress and support ongoing improvement. While the safety team is a critical component, it is important to realize that successful implementation of safety can only occur if safety is a priority for everyone in the organization, and not limited to the jurisdiction of the safety team.

It is valuable to utilize tools such as the Cultural Index Guide (Reason, 1997) to assess the status of the organization. The rating scale shown in Figure 5 is an extension of the framework put forth by Reason (1997) and also attributed to
Westrum (1991; 1999). The rating scale was subsequently revised to include additional interim categories for a safety ladder that includes pathological, reactive, calculative, proactive, and generative, and has been attributed to Hudson $(1998 ; 2003)$. Figure 5 can be used to assess the organizational culture, with ratings in each category provided by employees at all levels. This can also be used as a tool to track changes in organizational culture over time. Organizations with positive or generative cultures are the goal, and produce the optimal outcomes. Organizations with negative or pathological cultures can realize dramatic gains by making organizational changes to improve human factors sustainability. Purdue human factors research has found, very often, that executives will rate an organization as being more generative, whereas employees will rate the organization as being more pathological.

Regardless of the corporate policy, it is the local workplace culture and environment that ultimately impact the activities and results in the operational work envelope of the ramp.

\begin{tabular}{|c|c|c|c|}
\hline Category & $\begin{array}{l}\text { Pathological } \\
\text { (rating =1) }\end{array}$ & $\begin{array}{l}\text { Bureaucratic } \\
(\text { rating }=3 \text { ) }\end{array}$ & $\begin{array}{l}\text { Generative } \\
(\text { rating }=5 \text { ) }\end{array}$ \\
\hline $\begin{array}{l}\text { Response to } \\
\text { Safety } \\
\text { Violations }\end{array}$ & $\begin{array}{l}\text { No action or } \\
\text { inappropriate action }\end{array}$ & Reactive & Proactive \\
\hline Philosophy & $\begin{array}{l}\text { Don't want to know } \\
\text { about safety problems }\end{array}$ & $\begin{array}{l}\text { May not find out about } \\
\text { safety problems }\end{array}$ & $\begin{array}{l}\text { Actively seek out } \\
\text { safety problems }\end{array}$ \\
\hline $\begin{array}{l}\text { Safety } \\
\text { Messengers }\end{array}$ & $\begin{array}{l}\text { Whistle blowers are } \\
\text { "shot" }\end{array}$ & $\begin{array}{l}\text { Safety messengers } \\
\text { may be listened to if } \\
\text { they can get through } \\
\text { the bureaucracy }\end{array}$ & $\begin{array}{l}\text { Safety messengers are } \\
\text { trained and rewarded }\end{array}$ \\
\hline $\begin{array}{l}\text { Policy and } \\
\text { Communication }\end{array}$ & $\begin{array}{l}\text { Policy is minimal and } \\
\text { communication is } \\
\text { negative or absent }\end{array}$ & $\begin{array}{l}\text { Policy may exist but is } \\
\text { not translated into } \\
\text { practice; policy may } \\
\text { be extensively } \\
\text { documented but not in } \\
\text { a useful format due to } \\
\text { language and/or length }\end{array}$ & $\begin{array}{l}\text { Proactive } \\
\text { communication } \\
\text { addresses safety issues } \\
\text { in a useful way; } \\
\text { communication is up } \\
\text { and down the chain of } \\
\text { command in response } \\
\text { to challenges and } \\
\text { opportunities }\end{array}$ \\
\hline Responsibility & $\begin{array}{l}\text { Shared responsibility } \\
\text { with no clear chain of } \\
\text { command; if } \\
\text { everyone is } \\
\text { responsible, no one is } \\
\text { responsible and } \\
\text { accountable }\end{array}$ & $\begin{array}{l}\text { Compartmentalized } \\
\text { responsibility }\end{array}$ & $\begin{array}{l}\text { Responsibility is } \\
\text { shared at all levels but } \\
\text { specific responsibilities } \\
\text { are clearly defined for } \\
\text { each employee }\end{array}$ \\
\hline $\begin{array}{l}\text { Response to } \\
\text { Failure }\end{array}$ & $\begin{array}{l}\text { Punished or } \\
\text { concealed }\end{array}$ & Lead to local repairs & $\begin{array}{l}\text { Lead to far-reaching } \\
\text { reforms }\end{array}$ \\
\hline $\begin{array}{l}\text { Innovation and } \\
\text { New Ideas }\end{array}$ & Actively discouraged & $\begin{array}{l}\text { Often present } \\
\text { problems }\end{array}$ & Welcomed at all levels \\
\hline
\end{tabular}

Figure 5. Types of organizational culture (modified version of table developed by Reason,1997). 
The local work environment may vary from location to location, and even from shift to shift. Influencers of the local work environment are shown in Figure 6, based on the results of a survey conducted by Purdue University (Lopp \& Brazee, 2005). The team leader and most experienced peer are responsible for approximately $75 \%$ of the local culture, whereas the impact of the middle manager is negligible. Developing an effective team culture at the local level requires peer-to-peer communication that reinforces appropriate actions, must be facilitated by a positive workplace behavior, and is created by direct interaction and the influence of front line team leaders.

The importance of peers cannot be overstated, and due to this impact, it is important to identify "champions" who will reinforce appropriate attitudes and actions on the ramp, even when the supervisor is not present.

\section{Systematic Process}

Systematic process refers to the development of a system to support human factors sustainability. This can be accomplished by identifying accountability at each level in the organization. Accountability must address not only who is responsible, but also the span of control, expectations for performance, and associated measurements. A well-defined systematic process identifies appropriate measurements to ensure accountability and identifies an appropriate process for measuring and reporting measurements.

The systematic process must address accountability at every level in the organization, mapping back to specific roles and accountabilities for each position shown in Figure 4. For example, an executive management team must ensure corporate resources accommodate safety activities, and must hold directors and managers accountable for the development and implementation of safety policies and metrics that can be communicated up and down the chain of command. Managers are also typically

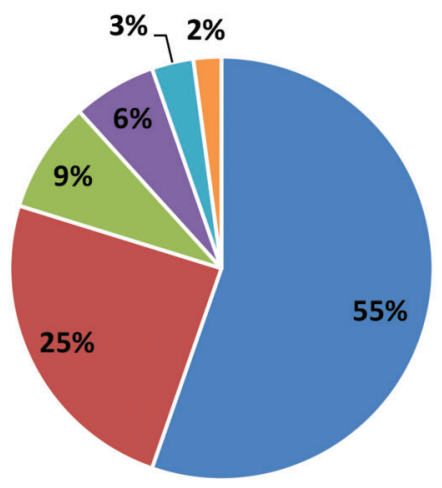

\section{- Team Leader \\ - Older Peers \\ - Other Team Coodinators}

Figure 6. Factors that influence local culture (Lopp \& Brazee, 2005). accountable for ensuring that appropriate training resources are provided for both supervisors and front line employees, and for ensuring that policies that have been developed are being followed consistently. The systematic process must also build in communication channels and metrics so the effectiveness of safety policies and practices can be assessed and modified, as necessary, on a continuing basis. Processes must include both formal policy and procedure, and also build in time for regular interaction to support a generative safety culture. Regular, scheduled interaction should include time for employees to provide feedback to supervisors regarding current practices, for supervisors to provide oversight of front line employees, for managers to meet with supervisors to review safety metrics and get feedback regarding ramp activities, and for managers to brief the executive team on safety performance and concerns.

\section{Measurements}

Measurements are critical to assuring progress is made and maintained with respect to human factors sustainability and other organizational goals. Measurements provide an objective and proactive means of assessing the systematic processes that have been developed. Measurements facilitate compliance and reduce errors and incidents at all organizational levels. Measurements will also provide a tool beyond injuries and property damage, which are "worst case" measurements that ideally will be avoided altogether. Measurements, while important, are not a substitute for incident investigation or reporting.

Measurements should be maintained in a database to support trend analysis and decision making and provide feedback on operational changes. Measurements should be developed in many areas-to assess resource allocation, policy implementation, and daily culture. Measurements may include employee ratings of organizational culture (per Figure 4), time and resources devoted to training, employee turnover, engagement in continuous improvement processes, 360 degree employee evaluations, and direct observation of compliance. It is importance to recognize the influence of the observation period and the random distribution of incidents. If one period has an unusually high rate of incidents, the following period is likely to have a reduced rate of incidents even if no countermeasures are implemented, due to the "regression-to-mean" effect.

Metrics to assess contributions to human factors sustainability should be incorporated into accountability dashboards not only for organizational units but also for individual employees. Each employee in an organization should be evaluated for their role in the human factor sustainability process. A quantitative and qualitative assessment component for human factors sustainability should be included in regular employee evaluations; just as employees are rated in terms of their productivity, 
communication skills, and other performance metrics, they should be rated in terms of their adherence to safety policy, participation in proactive human factors sustainability practices, and communication and support of other employees and peers (above and below them in the organizational chart). Relevant elements of Figure 5 can be incorporated into performance assessment documents for both individual employees and organizational units, as illustrated by the metrics shown in Figure 7.

In many cases, current measurements, if they exist at all, are focused on high stakes outcomes such as injuries and aircraft damage. This practice does not capture the many components that contribute to positive human factors sustainability and does not provide a way to measure the risk associated with current practices. Current measurements at a more detailed level, such as ramp audits, typically focus on completion of the task for the team, without documenting individual performance or capturing the order of activities. Metrics such as documentation of daily safety briefs and the appropriateness of their content (e.g., tailoring content to the specific team, activities, and weather conditions) were typically not used prior to implementation of the proposed framework.

\section{Education}

It is important that education be ongoing and match the daily needs of the employee at each level in the organization. Measurements through assessments can identify areas where additional education is needed, as well as document the effectiveness of training programs. Assessments can be made in all facets, from technical components of operation, to behavioral science and production management skills. Assessment may include written assessments as well as observations. Behavioral science research indicates that behavior is shaped primarily by two factors: antecedents and consequences (University of Kansas, n.d.). Antecedents occur before the behavior, and include training, policy, and promised incentives or disincentives. Consequences occur after the behavior and include feedback (positive or negative), bonuses, reprimands or disciplinary action. As shown in Figure 8, antecedents have only a $20 \%$ influence on behavior, whereas consequences have an $80 \%$ influence on behavior. To be most effective, consequences should be positive (vs. negative), immediate (vs. future) and certain (vs. uncertain). Reinforcement of behavior through appropriate consequences is an important concept in human factors sustainability. Building in positive, immediate, and certain impact into the culture requires a system that accommodates first level recognition, reporting, and reaction. This can only be accomplished if the supervisor is directly supervising the line or ramp operations, rather than engaged with administrative tasks such as email or paperwork in an office, which makes him or her unavailable to the front line employees. Middle management can support all employees by assuring that adequate supervision and training is provided.

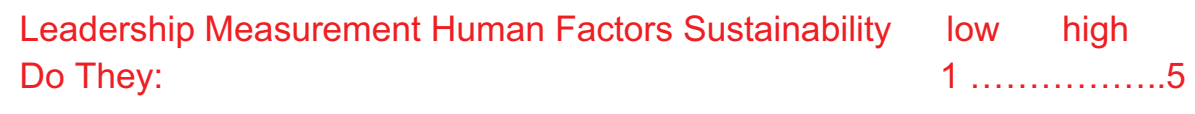

\begin{abstract}
GM/Directors
Participate in announcing and supporting HF program

Provide financial resource and management time for HF program

Follow-up on HF measurement program and provide input for improvement

Work with Mangers in providing guidance in HF culture influence
\end{abstract}

Total

Managers

Support HF program briefings and participate in shift briefings

Monitor the HF implementation process

Measure shifting briefings structure and activity

Measure safety culture and provide input to supervisors

Develop, record, and report HF performance results

Walkthe floor and provide a positive HF influence

Work with supervisors in providing HF guidance

\title{
$1^{\text {st }}$ Line Supervisors
}

Conduct HF performance reports

Integrate HF as equal importance in shift briefings

Provide daily positive HF influence in employee work environment

Monitor HF behaviors and provide immediate feedback

Total

Figure 7. Human factors (HF) sustainability metrics must be identified and assessed at every organizational level. 


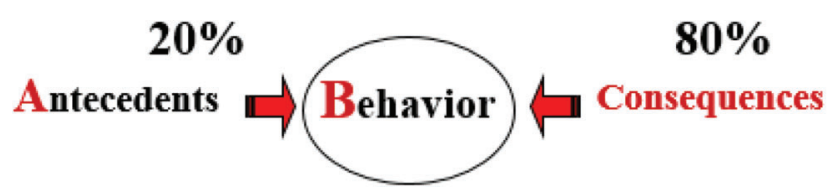

Figure 8. Consequences have a greater influence on behavior than antecedents.

Feedback also occurs at other levels in the organization. Management communicates organizational priorities not only through mission statements and policies, but also through their own behaviors in the work environment. Corrective and reinforcing feedback are key at all organizational levels. Letting inappropriate behaviors "slide" just once, which may be direct or indirect through a lack of feedback, results in a culture that accepts the inappropriate behavior. When a supervisor or management reinforces productivity over a possible human factors infraction event, there is a large negative impact developing in a positive safety culture.

Training and education must be ongoing, not only through periodic, scheduled, and formal training, but also through less formal daily feedback at all organizational levels. Safety training and, equally important, reinforcement of a culture consistent with human factors sustainability must permeate every level of the organization.

Safety learning must be conducted as part of the work experience through a variety of activities, including:

- Mentoring: includes both formal and informal programs.

- Briefings: includes reporting of measurements as well as ongoing training briefings.

- Feedback: includes both positive and corrective feedback, which is most effective when issued immediately and constructively.

- Peer coaching: includes feedback on all activities to anticipate, celebrate, and remediate actions that have occurred.

Values and beliefs must be demonstrated not only through policy statements, but also through employee behaviors in "real-time," which means immediate and appropriate feedback, both positive and corrective. This can only be achieved if all employees understand appropriate actions and are trained in the provision of appropriate feedback in terms of timeliness, positive feedback, and respectful communication when corrective action is required for peers, subordinates, and superiors. This often requires additional training and attention to "soft" or "people" skills, in addition to training that focuses on technical, operational, or managerial skills.

\section{Example Applications}

Below are example applications that illustrate the pathological, bureaucratic and generative environment for human factor sustainability.

Example Application 1. A representative of the safety team is on the ramp with an airline director and a manager.
A front line employee is observed standing on the baggage loader when a ladder should be used for safety.

Pathological response 1. The incident is witnessed with no response. It is the responsibility of the front line employees and supervisors to manage themselves.

Impact: The lack of corrective feedback provides a clear message that safety is not a priority for the safety team, directors, or managers.

Pathological response 2. The safety team member directly approaches the employee and explains why it is important to use a ladder for safety, and waits until the employee corrects his behavior.

Impact: This usurps the supervisor and implicitly transfers responsibility for safety from the supervisor to the safety team.

Bureaucratic response 1. The safety team member sends an email to the supervisor, documenting the occurrence, including date, time, and location.

Impact: The event is documented, but the lack of immediate corrective feedback communicates that safety is a policy rather than practice-oriented activity.

Generative response 1 . The safety team member directly approaches the supervisor so the supervisor can immediately address the occurrence with corrective feedback.

Impact: The immediate corrective feedback while the director and manager delay their activities communicates the importance of safety implementation; utilization of the supervisor for corrective feedback maintains the authority of the supervisor for ramp safety.

Example Application 2. Briefings conducted by supervisors occur daily and weekly to address ongoing activities and emphasize priorities.

Pathologic activity 1. The supervisor discusses productivity and on-time goals at daily and weekly meetings, reflecting the metrics he must provide to his manager and director.

Impact: Safety is neglected as productivity and on-time goals are prioritized throughout the organization.

Bureaucratic activity 2. The supervisor discusses productivity and on-time goals at daily and weekly meetings. Safety is mentioned in a perfunctory way and may be minimally addressed with reference to company policy, especially after an injury or an incident resulting in damage. 
Impact: Safety may be nominally acknowledged, but without a structure or human factors sustainability to support it, other more immediate concerns take precedence.

Generative activity 1. The supervisor incorporates safety in a meaningful way in all briefings. Safety policy is discussed not only in the context of policy, but also in the context of actual practices as they relate to daily activities. Front line employees are expected to participate in hazard evaluations associated with tasks, such as the hazard matrix shown in Figure 9, as well as support development of safety policy that reflects actual practice. Front line employee input is provided to management through the supervisor, addressing "near misses" and other safety information that may not be captured by traditional injury reports. Management and directors provide information regarding incidence and costs associated with injury regularly to supervisors and front line employees. Executive and director-level employees assure that resources allow management and supervisors to devote needed time and resources to safety. Training programs address risks and best safety practices for daily tasks and special tasks. Risk matrices and safety best practices are integrated into job assignments to keep safety on the forefront of employee consciousness. Special topics in daily and weekly briefings are supported by safety data from the organization, as well as training modules that highlight risks and best safety practices.

Impact: Safety practices are "owned" at all levels and reflect data-driven decisions. Employees at all levels participate and are held accountable. Safety practices and policies reflect actual best practices. Safety culture is promoted and reinforced by daily activities.

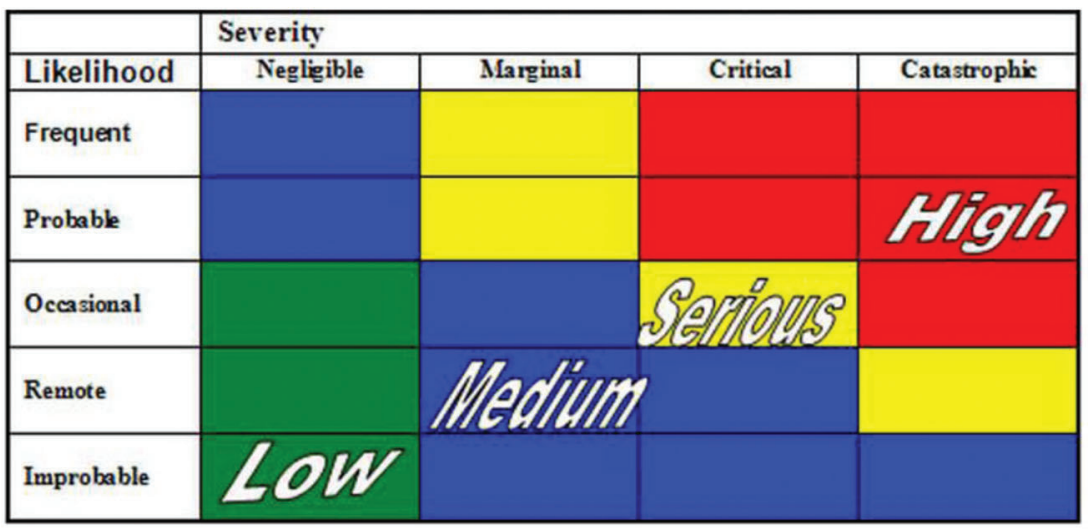

a) FAA hazard risk assessment matrix (n.d.)

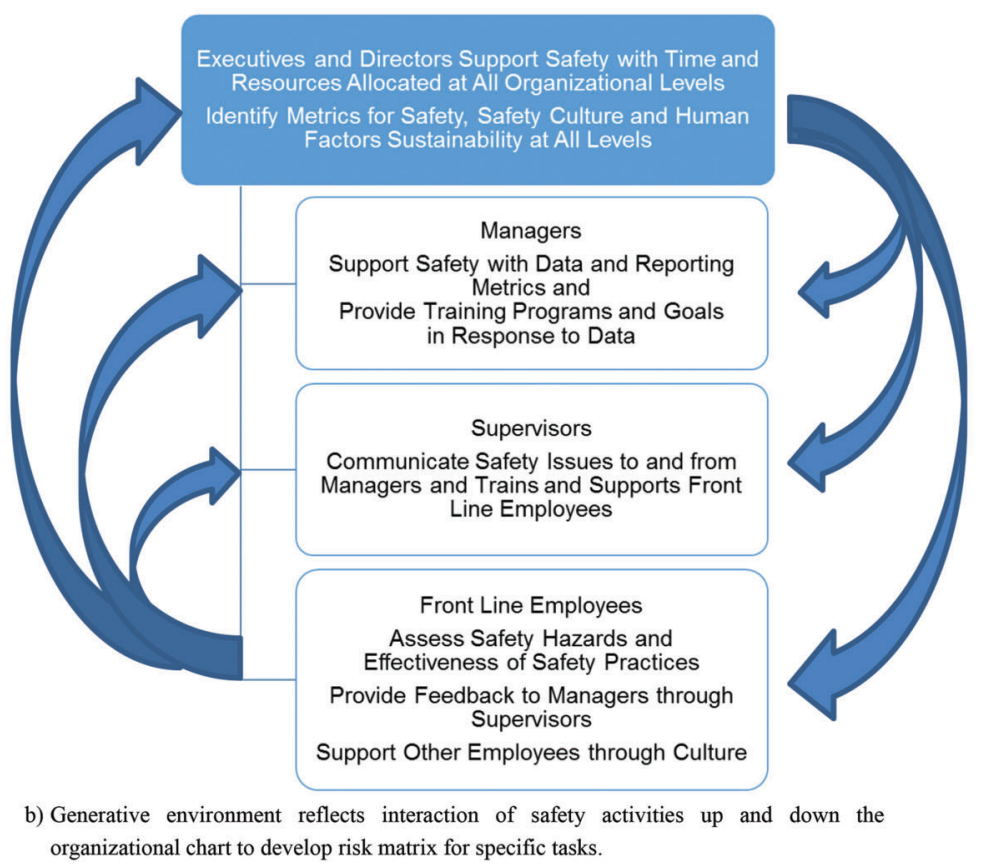

Figure 9. Hazard risk assessment matrix and safety activities to develop matrix for specific tasks in generative environment. 


\section{Conclusions}

The effectiveness of any organization is limited by its ability to conduct its mission safely and efficiently. This paper identifies four key components that are necessary to successfully implement human factors sustainability into aviation ramp operations based on the experience of Purdue researchers, their observations of ramp activities, and their consultations with airline industry representatives. Human factors sustainability not only increases safety and performance, but also results in an organization with a generative or progressive culture that will facilitate continuous improvement and employee satisfaction.

1. Organizational Infrastructure

2. Systematic Process

3. Measurements

4. Education

Evaluation of an organization and its policies and practices relative to these four key components provides a structure to outline the roles and responsibility of each person in the organization from the CEO to front line worker. The proposed framework provides a structure to support human factors sustainability and a positive safety culture.

\section{References}

Boeing. (2014). Commercial airplane jet prices, retrieved from http:// www.boeing.com/boeing/commercial/prices/

Bureau of Labor Statistics. (2010). Incidence rates of nonfatal occupational injuries and illnesses by industry and case type. 2010. Retrieved from http://www.bls.gov/iif/oshwc/osh/os/ostb2813.pdf

Bureau of Labor Statistics. (2013). Employer-reported workplace injuries and illnesses-2012. Retrieved from http://www.bls.gov/news.release/ archives/osh_11072013.pdf

Chen, C. \& Chen, S. (July 2012). Scale development of Safety Management System evaluation for the airline industry. Accident Analysis \& Prevention, 47, 177-181.

CPI Inflation Calculator. (n.d.). Retrieved October 18, 2014 from http:// data.bls.gov/cgi-bin/cpicalc.pl

Giovanni, D. (2011). Regulations Surrounding Ground Handling and Ramp Safety, International Airport Review, 11 (6), 21-23.
Federal Aviation Administration (FAA). (n.d.). Risk Assessment Matrix. Retrieved from http://www.faasafety.gov/gslac/alc/libview_normal. aspx $?$ id $=6877$

FAA. (2007). Introduction to Safety Management Systems (SMS) for airport operators (AC 150/5200-37). Retrieved from http://www.faa. gov/documentLibrary/media/advisory_circular/150-5200-37/150_ 5200_37.pdf

FAA. (2014). Safety Management System components. Retrieved from https://www.faa.gov/about/initiatives/sms/explained/components/

Hudson, P. T. W. (September 14, 1998). Safety cultures in aviation. Keynote address at European Aviation Psychology Conference. Vienna.

Hudson, P. T. W. (2003). Aviation safety culture. Journal of Aviation Management, 3. 27-48.

Jeffries, B. (August 2005). The accidental organization. New Zealand Management, 52 (7).

Leigh, J. (2011). Economic burden of occupational injury and illness in the United States. Milbank Quarterly. Retrieved from http://www.ncbi. nlm.nih.gov/pubmed/22188353

Liou, J. J. H., Yen, L. \& Tzeng, G. (January 2008). Building an effective Safety Management System for airlines. Journal of Air Transport Management, 14 (1).

Lopp, D. W., \& Brazee, C. A. (2005). The essential elements for safety (and productivity) improvements in aviation environments. Canadian Aviation Safety Seminar (CASS 2005). Vancouver, BC.

National Safety Council. (2011). Transportation mode comparisons. Injury Facts. Retrieved from http://static.mgnetwork.com/rtd/pdfs/20110610_ deathrates11.pdf

Reason, J. (1997). Managing the risks of organizational accidents. Aldershot, England: Ashgate Publishing.

Reason, J. (2000). Human error: Models and management. British Medical Journal (BMJ) 2000 (320). 768-770.

Thomas, G. (2004). DuPont safety resources from US Department of Labour statistics, Retrieved from http://www.iasa.com.au/folders/ Safety_Issues/RiskManagement/gatecrashing.html

University of Kansas, (n.d.). Antecedent-behavior-consequence (ABC) chart. Retrieved from http://www.specialconnections.ku.edu/? $\mathrm{q}=$ behavior_plans/functional_behavior_assessment/teacher_tools/ antecedent_behavior_consequence_chart

Vandel, B. (2004). Equipment damage and human injury on the apron-Is it a cost of doing business? Proceedings from ISASI '04: The 35th Annual International Seminar on Air Safety through Investigation: Gold Coast, Australia. Retrieved from http://www.isasi.org/ Documents/library/Seminar-Proceedings/Proceedings-2004.pdf

Westrum, R. (1991). Cultures with requisite imagination. In J. Wise, P. Stager, J. Hopkin, (Eds.), Verification and validation in complex manmachine systems (pp. 401-416). New York: Springer.

Westrum, R., \& Adamski A. J. (1999). Organizational Factors Associated with Safety and Mission Success in Aviation Environments. In D. J. Garland, J. A. Wise, V. D. Hopkin (Eds.), Handbook of Aviation Human Factors (pp. 67-104). Mahwah, NJ: Lawrence Erlbaum. 